\title{
MENTAL HEALTH SERVICES 2010 MEDICATION
}

\section{INTRODUCTION}

Under the Mental Health Act 2001 the Inspectorate carries out a review of mental health services in the state and furnishes a report on the quality of care and treatment given to persons in receipt of mental health services. In 2010 the Inspectorate included a review of prescribing practices in approved centres which comprised of acute units and long stay units. This followed a similar review in 2008 which was contained in the Report of the Inspector of Mental Health Services 2008.

During the inspections of 2010 the Inspectorate collected prescription sheets for both acute and long-stay residents from each adult approved centre. In total 2,340 prescription sheets were collected from 63 approved centres. There were 1,216 prescription sheets from acute units and 1,124 prescription sheets from long-stay units. The prescription sheets were collected on the day of inspection. The emphasis in this analysis was on the quality of the prescription sheets, use of benzodiazepines, and polypharmacy in the use of antipsychotics.

\section{PRESCRIPTION SHEETS}

In the majority of prescription sheets the signature of the prescriber was illegible and there was no use of printed versions of prescribers' names. Some, but not all units had a signature bank available. In a very small number of prescriptions the medical staff documented their Medical Council Registration Number. This was an excellent development in identifying prescribers.

In many of the prescription sheets a mixture of generic names and commercial names of drugs were used, some within the same prescription sheet. In many prescriptions it was also unclear when medication had first been prescribed and there was no way of telling the length of time a resident had been on medication. This was of particular concern regarding the use of benzodiazepines. In the vast majority of prescription sheets there was no space for indications for use of PRN (as required) medication.

In $42 \%$ cent of approved centres a card index was used as a prescription sheet. This was a one-sheet prescription which was old fashioned and not used in other medical or surgical specialities. Administration of medication was signed on separate sheets and could get mislaid. In most cases PRN medication, regular medication and depot medication were all in one area making prescriptions difficult to follow. This type of prescription sheet tended to be untidy. A significant number did not have the resident's date of birth recorded and others did not incorporate the name of the hospital or unit. It was particularly noticeable that where the card index system was 
used there was much crossing out and writing underneath discontinued prescriptions. The result was difficult to follow and had the potential to lead to medication errors. There was no facility to ensure regular review of long-term medication. There was minimal space to document patient identifiers and in most cases there was no room for a photograph of the patient. There was little to commend this form of prescription sheet.

The remainder (58\%) of the approved centres used a booklet form of prescription sheet. This resulted in prescriptions being easier to read. PRN, regular medication and depot medication were documented separately and there was less potential for errors. There was more space for patient identifiers and many centres where there were long stay residents attached a photograph to the prescription sheets. The format of the booklet prescription sheet meant that long-term medications had to be reviewed regularly and re-written where necessary.

\section{BENZODIAZEPINES (BZDs)}

Benzodiazepines are used as medication for anxiety and as night sedation. They may be prescribed as a regular dose and/or as a when required (PRN) dose. They should only be used for the treatment of anxiety symptoms after alternative therapies have been tried. In some cases benzodiazepines are also used effectively to control epilepsy. Benzodiazepines should only be used if the anxiety is severe, overwhelming and distressing. International guidelines recommend that people only remain on benzodiazepines for a period of a maximum of two to four weeks as they can cause dependency resulting in difficulties in discontinuing the medication after a certain length of time. A small number of people may require benzodiazepines in the longer term and this includes people who are already severely dependent on these drugs. Methods are available for withdrawing people from benzodiazepines where they have been used for longer periods of time. In short benzodiazepines should be used for a specific purpose, for the shortest possible length of time and in the smallest possible dose.

During the inspections of 2010 it was found that the use of benzodiazepine in both acute and long stay units was widespread. In total $57 \%$ of in-patients were prescribed benzodiazepines. Of these in-patients $62 \%$ of patients were on regular benzodiazepines and 62\% were on PRN benzodiazepines. Benzodiazepine prescribing ranged from $2 \%$ in one unit to $97 \%$ in another unit.

There is very little research internationally on the use of benzodiazepines in psychiatric in-patient units. Findings of other studies have varied widely from $10 \%$ to $83 \%$ of patients prescribed benzodiazepines in in-patient units. A recent Irish study found that benzodiazepines were prescribed to $51 \%$ of patients regularly and $66 \%$ of patients PRN in an acute adult in-patient unit. 
The practice of combining more than one benzodiazepine despite the lack of evidence of therapeutic value was highlighted in the 2008 Report of the Inspector of Mental Health Services. In 2010 the practice of using more than one benzodiazepine had decreased from $43 \%$ to $24 \%$ in acute units and from $37 \%$ to $27 \%$ in long stay units.

As in 2008 the vast majority of PRN prescriptions for benzodiazepines had no time limit and had no review date written into the prescription. In effect, this allowed PRN benzodiazepines to be administered for extended periods of time without review. Most prescriptions did not specify indications for administering PRN medication, but most specified how often it could be given throughout a 24-hour period.

\section{PRESCRIPTIONS OF BENZODIAZEPINES IN ACUTE UNITS}

Number of acute units

Total number of prescriptions

\begin{tabular}{|l|l|l|}
\hline & $\mathbf{2 0 0 8}$ & $\mathbf{2 0 1 0}$ \\
\hline $\begin{array}{l}\text { Number of acute } \\
\text { units examined }\end{array}$ & $\mathbf{1 8}$ & $\mathbf{3 7}$ \\
\hline $\begin{array}{l}\text { Percentage of all } \\
\text { residents on } \\
\text { Benzodiazepines }\end{array}$ & $\mathbf{6 8 \%}$ & $\mathbf{6 1 \%}$ \\
\hline $\begin{array}{l}\text { Percentage of } \\
\text { residents on } \\
\text { regular } \\
\text { prescriptions of } \\
\text { benzodiazepines }\end{array}$ & $64 \%$ & $61 \%$ \\
\hline $\begin{array}{l}\text { Percentage of } \\
\text { residents on PRN } \\
\text { prescriptions of } \\
\text { benzodiazepines }\end{array}$ & $63 \%$ & $60 \%$ \\
\hline $\begin{array}{l}\text { Percentage of } \\
\text { residents on more } \\
\text { than one } \\
\text { benzodiazepine }\end{array}$ & $43 \%$ & $24 \%$ \\
\hline
\end{tabular}




\section{PRESCRIPTIONS OF BENZODIAZEPINES IN LONGSTAY UNITS}

Number of units

33

Total number of prescriptions
1,124

\begin{tabular}{|l|l|l|}
\hline & $\mathbf{2 0 0 8}$ & $\mathbf{2 0 1 0}$ \\
\hline $\begin{array}{l}\text { Number of acute units } \\
\text { examined }\end{array}$ & $\mathbf{2 3}$ & $\mathbf{3 3}$ \\
\hline $\begin{array}{l}\text { Percentage of all } \\
\text { residents on } \\
\text { Benzodiazepines }\end{array}$ & $\mathbf{6 0 \%}$ & $\mathbf{5 4 \%}$ \\
\hline $\begin{array}{l}\text { Percentage of residents on } \\
\text { regular prescriptions of } \\
\text { benzodiazepines }\end{array}$ & $71 \%$ & $64 \%$ \\
\hline $\begin{array}{l}\text { Percentage of residents on } \\
\text { PRN prescriptions of } \\
\text { benzodiazepines }\end{array}$ & $56 \%$ & $63 \%$ \\
\hline $\begin{array}{l}\text { Percentage of residents on } \\
\text { more than one } \\
\text { benzodiazepine }\end{array}$ & $37 \%$ & $27 \%$ \\
\hline
\end{tabular}

\section{PRESCRIPTION OF ANTIPSYCHOTIC MEDICATION}

People who are admitted to psychiatric units are often those with the most complex needs and provide the greatest challenges in drug therapy. Antipsychotic medication is used to treat symptoms of psychosis and can be used in acute psychotic states, schizophrenia, mania or hypomania in bipolar disorder and in depression.

Antipsychotics are given either orally or by depot injection. Some patients respond well to antipsychotic medication while others receive minimal benefit. In this review $80 \%$ of residents were receiving antipsychotic medication.

Clinical guidelines advise against prescribing more than one antipsychotic medication with limited exceptions. Ideally one antipsychotic should be used but there are cases where two antipsychotics may be indicated. Combined antipsychotics are used for a number of reasons. These include control of disturbed behaviour, poor response to antipsychotic monotherapy, to cover a period of acute positive symptom exacerbation and while switching from one antipsychotic to another. The efficacy of using two or more antipsychotics has not been proven and there are no double blind randomised clinical trials. By using more than one antipsychotic the side-effect base broadens depending on the different agents used. International studies show that about $44 \%$ of in-patients are on two or more antipsychotic medications. In this review $28 \%$ of residents were receiving two or more antipsychotic medications. 
Combining antipsychotics is a major cause of high dose prescribing. In this survey $10 \%$ of residents on antipsychotic medication were on doses of antipsychotic above the recommended dosage. U.K. studies have shown that the prescription of high dose antipsychotic medications above recommended levels reveals a rate of about $20 \%$.

\section{PRESCRIPTIONS OF ANTIPSYCHOTIC MEDICATION IN ACUTE UNITS}

Number of units

37

Total number of prescriptions

1,216

\begin{tabular}{|l|l|l|}
\hline & $\mathbf{2 0 0 8}$ & $\mathbf{2 0 1 0}$ \\
\hline $\begin{array}{l}\text { Number of acute } \\
\text { units examined }\end{array}$ & $\mathbf{1 8}$ & $\mathbf{3 7}$ \\
\hline $\begin{array}{l}\text { Percentage of } \\
\text { residents on } \\
\text { Antipsychotics }\end{array}$ & $\mathbf{7 6 \%}$ & $\mathbf{7 9 \%}$ \\
\hline $\begin{array}{l}\text { Percentage of } \\
\text { those residents on } \\
\text { more than one } \\
\text { antipsychotic }\end{array}$ & $35 \%$ & $22 \%$ \\
\hline
\end{tabular}

PRESCRIPTION OF ANTIPSYCHOTIC MEDICATION IN LONG-STAY UNITS

Number of units

33

Total number of prescriptions

\begin{tabular}{|l|l|l|}
\hline & $\mathbf{2 0 0 8}$ & $\mathbf{2 0 1 0}$ \\
\hline $\begin{array}{l}\text { Number of acute } \\
\text { units examined }\end{array}$ & $\mathbf{2 3}$ & $\mathbf{3 3}$ \\
\hline $\begin{array}{l}\text { Percentage of } \\
\text { residents on } \\
\text { Antipsychotics }\end{array}$ & $\mathbf{7 6 \%}$ & $\mathbf{8 1 \%}$ \\
\hline $\begin{array}{l}\text { Percentage } \\
\text { residents on more } \\
\text { than one } \\
\text { antipsychotic }\end{array}$ & $46 \%$ & $35 \%$ \\
\hline
\end{tabular}




\section{PROGRESS ON 2008 RECOMMENDATIONS}

1. Each approved centre should conduct an audit on their use of benzodiazepines.

There was evidence from a small number of approved centres that an audit had taken place on benzodiazepines prescribing. A small number of other approved centres had undertaken a general audit on prescriptions. There was evidence that benzodiazepine prescribing had decreased in these approved centres.

2. The card index system of prescribing should be discontinued.

Forty two per cent of units continued to use the card index system of prescribing.

3. It should be ensured that non-consultant hospital doctors are proficient in the safe use of benzodiazepines and in writing prescriptions.

In approved centres where audits had been carried out there was evidence that benzodiazepine prescribing had reduced and the quality of prescribing had increased.

4. Each signature on a prescription should have a corresponding printed name. Some prescription sheets incorporated a signature bank. The card index system of prescribing had no incorporated signature bank. A small number of prescribers used Medical Council Registration Numbers with their signatures.

5. Each prescription should specify the residents name, date of birth and the name of the unit and approved centre.

This was done in the majority of cases where booklet prescription sheets were used. The card index system was not as likely to have all identifiers present. 


\section{CONCLUSION}

The standard of prescribing was poor in areas where the card index method of prescribing was used. This was in nearly half of the units inspected. The booklet form of prescribing was clearer, safer and allowed for more frequent reviews of medication. The use of benzodiazepines in both acute and long stay units had decreased slightly since 2008 but continued to be high in many units. The lack of therapeutic services and programmes as well as poor knowledge about the problems of benzodiazepine prescribing may account for this. The practice of using more than one benzodiazepine continued and $26 \%$ of residents are on more than one benzodiazepine. The practice of combining antipsychotic medication has decreased since 2008 and is less than that seen in international practice. The use of high dose antipsychotic medication is low compared with international studies. This may reflect an awareness of the dangers of polypharmacy and high dose antipsychotic prescribing among psychiatrists.

\section{RECOMMENDATIONS 2010}

1. The card index system of prescribing should be discontinued.

2. Each approved centre should conduct regular audits of medication prescribing.

3. Medical Council Registration Numbers should be used when signing prescriptions.

4. PRN medication should be regularly reviewed.

5. Indications for PRN medications should be documented.

6. Training and education in safe prescribing should take place. 


\section{REFERENCES}

1. National Institute for Clinical Excellence 2005. Clinical Guidance 25. Violence: the short term management of disturbed/violent behaviour in psychiatric inpatient settings and emergency departments. National Institute for Clinical Excellence, London.

2. Benzodiazepines: risks, benefits or dependence. A re-evaluation. Council Report CR 59 January 1997. Royal College of Psychiatrists.

3. Benzodiazepines: Good Practice Guidelines for Clinicians. Department of Health and Children 2002.

4. Report of the Benzodiazepine Committee 2002. Department of Health and Children.

5. Hallaghan B., Murray I., McDonald C. Benzodiazepines and hypnotic prescribing in an acute adult psychiatric in-patient unit. The Psychiatrist Jan 2009: Vol 33: Issue 1.

6. Paton C, Banham S, Whitmore J Benzodiazepines in schizophrenia. Is there a trend towards long term prescribing? Psychiatric Bulletin 2000 24: 113-115

7. Summers J, Brown K.W. Benzodiazepine prescribing in a psychiatric hospital. Psychiatric Bulletin (1998) 22 480-483

8. Haw C, Stubbs J. Benzodiazepines a necessary evil? A survey of prescribing at a specialist UK psychiatric hospital. Journal of Psychopharmacology 2007; $21 ; 645$

9. Wheeler, A., Kairuz, T., Sheridan, J. \& McPhee, E. (2007) Sedative-hypnotic treatment in an acute setting: Comparison with best practice guidance.

Pharmacy World and Science 29, 603-610

10. The Maudsley Prescribing Guidelines. $10^{\text {th }}$ edition. David Taylor, Carol Paton, Shitij Kapur.

11. Consensus statement on high-dose antipsychotic medication. Council Report CR138. May 2006. Royal College of Psychiatrists. 
12. Freudenreich O, Goff DC. Antipsychotic combination therapy in schizophrenia. A review of efficacy and risks of current combinations. Acta Psychiatr Scand 2002: 106: 323-330.

13. Centorrino F., Goren JL, Hennen J, Salvatore P, Kelleher JP, Baldessarini RJ. Multiple versus single antipsychotic agents for hospitalised psychiatric patients: case control study of risks versus benefits. Am J Psychiatry 2004: 161: 700-6.

14. Paton C. Barnes T, Cavanagh M. Taylor D. Lelliot P. High dose and combination antipsychotic prescribing in acute adult wards in the U.K: the challenges posed by p.r.n. prescribing. The British Journal of Psychiatry (2008) 192: 435-439.

15. Correll CU, Rummel-Kluge C,Corves C, Kane JM, Leucht S. Antipsychotic combinations vs monotherapy in Schizophrenia: a meat-analysis of randomized controlled trials. Schizophrenia Bulletin. Advance Access April 21 2008.

16. Chan J, Sweeting M. Review: Combination therapy with non-clozapine atypical antipsychotic medication: a review of current evidence. J Psychopharmacology 2007; 21; 657.

17. Stahl S Antipsychotic polypharmacy: evidence based or eminence based? Acta Psychiatr Scand 2002; 106: 321-322.

18. National Institute of Clinical Excellence. Core interventions in the treatment and management of schizophrenia in adults in primary and secondary care.

19. Harrington M, Lelliott C, Paton C, Ochoka C, Duffett R, Sensky T. The result of a multi-centre audit of the prescribing of antipsychotic drugs for inpatients in the U.K. Psychiatric Bulletin 2002;26:414-18. 